\title{
Pharmacodynamics of cisatracurium in the intensive care unit: an observational study
}

Eric Dieye ${ }^{1}$, Vincent Minville $^{1 *}$, Karim Asehnoune ${ }^{2}$, Claude Conil ${ }^{1}$, Bernard Georges ${ }^{1}$, Pierre Cougot ${ }^{1}$, Olivier Fourcade ${ }^{1}$ and Jean-Marie Conil ${ }^{1}$

\begin{abstract}
Background: Data from previous studies indicate that optimal conditions for intubation are met 120 seconds after administration of $0.15 \mathrm{mg} \cdot \mathrm{kg}^{-1}$ cisatracurium $(E D 95 \times 3)$ following the induction of anesthesia. The aim of this study was to compare the doses required for complete paralysis after induction of anesthesia in ICU patients with the dose used in patients undergoing elective surgery.

Methods: Seventeen ICU patients undergoing percutaneous tracheostomy and 17 patients undergoing an elective surgical procedure under muscle relaxation were included. In both groups, an initial intravenous bolus of cisatracurium besylate was given at a dose of $0.15 \mathrm{mg} . \mathrm{kg}^{-1}$ followed by repeated boluses of $0.03 \mathrm{mg} . \mathrm{kg}^{-1}$ every four minutes. The objective was to obtain no response to the train-of-four (TOF). The contractile response of the corrugator supercilii muscle was monitored every minute by observing the TOF in response to a peripheral nerve stimulator with a constant current set to $60 \mathrm{~mA}$.
\end{abstract}

Results: After the initial dose of cisatracurium, none of ICU patients (0/17) versus 15/17 of the elective surgery patients were completely paralyzed $(P<0.0001)$. There was a delay in the onset of neuromuscular blockade among the ICU patients. The cumulative doses of cisatracurium were significantly higher in the ICU group with $38 \pm 14 \mathrm{mg}$ (that is, $10 \pm 4.7 \mathrm{ED} 95)$ versus $11 \pm 2 \mathrm{mg}$ (that is, $3 \pm 0.3 \mathrm{ED} 95)$ in the elective surgery group $(P<0.0001)$.

Conclusion: The dosing of cisatracrurium for ICU patients, which is based on the dose recommended for elective anesthesia, is unsuitable because the onset is too slow. This phenomenon is probably caused by changes in the pharmacodynamics and pharmacokinetics. These data suggest that neuromuscular monitoring should be used in the ICU.

Keywords: Cisatracurium; ICU; Current anesthetic practice; Neuromuscular monitoring

\section{Background}

Although the use of neuromuscular blocking agents in the ICU is still a matter of ongoing debate, they continue to be frequently used. For example, in patients under volume controlled ventilation, a transient curarization can be used for brief diagnostic or therapeutic procedures in order to avoid the hemodynamic consequences of deep sedation. Also, in acute respiratory distress syndrome (ARDS) patients, a prolonged curarization of 48 hours or more is beneficial regarding systemic oxygenation, even in

\footnotetext{
* Correspondence: minville.v@chu-toulouse.fr

'Department of Anesthesiology and Intensive Care Medicine, Faculté de Médecine Toulouse-Rangueil, EA 4564-MATN, Institut Louis Bugnard (IFR 150), CHU Toulouse, Université Toulouse III Paul Sabatier, F-31000 Toulouse, France

Full list of author information is available at the end of the article
}

patients well-adapted to their ventilator [1]. Because of its pharmacokinetic properties, cisatracurium, a nondepolarizing neuromuscular blocking agent of the benzylisoquinoline family, is a popular choice in the ICU since it is (at physiological $\mathrm{pH}$ and temperature) rapidly degraded by Hoffmann elimination, yielding two metabolites without muscle relaxant properties: laudanosine and quaternary monoacrylate. Impaired renal or liver function has little influence on the pharmacokinetics of this drug $[2,3]$. The volume of distribution of cisatracurium is limited to the extracellular fluid $\left(144 \mathrm{~mL} \cdot \mathrm{kg}^{-1}\right)$, total plasma clearance is approximately $5.3 \mathrm{~mL} \cdot \mathrm{min}^{-1} \cdot \mathrm{kg}^{-1}$, and the elimination half life is between 22 and 30 minutes $[4,5]$.

In both the ICU and during anesthesia, the train-of-four (TOF) is the most widely used method of monitoring

\section{实}

(c) 2014 Dieye et al.; licensee Springer. This is an open access article distributed under the terms of the Creative Commons Attribution License (http://creativecommons.org/licenses/by/2.0), which permits unrestricted use, distribution, and reproduction in any medium, provided the original work is properly cited. 
neuromuscular function [6-11]. The ED95 of cisatracurium is the dose required to produce a $95 \%$ twitch height depression for the first twitch response of the adductor pollicis muscle after stimulation of the ulnar nerve, and is approximately $0.05 \mathrm{mg} \cdot \mathrm{kg}^{-1}$ of body weight during anesthesia with hypnotics and opioids (thiopental/midazolam/fentanyl) [12,13]. Optimal conditions for intubation are met 120 seconds after the administration of $0.15 \mathrm{mg} \cdot \mathrm{kg}^{-1}$ cisatracurium $(3 \times$ ED95) during induction of anesthesia (for 89 to $100 \%$ of patients) [14,15]. After administration of $0.20 \mathrm{mg} \cdot \mathrm{kg}^{-1}$ cisatracurium $(4 \times \mathrm{ED} 95)$, optimal conditions are met within 90 seconds (for 95 to $100 \%$ of patients) [15]. However, all the above studies were done on patients scheduled for elective surgery and thus these recommendations may not be appropriate for ICU patients where a variety of factors can affect the pharmacokinetics and pharmacodynamics of muscle relaxants: liver and/or kidney failure; hypothermia; fluid and electrolyte imbalances $[16,17]$; disorders of acid-base balance; as well as potential drug interactions (for example, aminoglycosides, steroids) [18]. This could indeed explain the observation that in clinical practice, higher doses of cisatracurium are often needed for ICU patients to obtain a clinically acceptable degree of neuromuscular blockade $(\mathrm{TOF}=0)$.

The aim of this study was to compare the doses required for complete paralysis after induction of anesthesia in ICU patients with the dose used in patients undergoing elective surgery.

\section{Methods}

Thirty-four patients were enrolled in this prospective observational study. The study was performed in accordance with the Helsinki Declaration. The Local Ethics Committee (comité d'éthique de la recherche des Hôpitaux de Toulouse: registration number 23-0412) approved the study. Because there was neither a randomization involved nor a change in the current local clinical practice (TOF monitoring is part of the routine medical care in the ICU and for surgical patients requiring a muscle relaxant), the institutional review board waived the requirement for a written informed consent.

Seventeen consecutive ICU patients who were paralyzed for a percutaneous tracheostomy were included. The indication for the tracheostomy was an anticipated length of mechanical ventilation for more than 15 days. ICU patients were stable (no acute hepatic or renal failure), euvolemic and on low dose catecholamine infusion (norepinephrine $<1 \mathrm{mg} \cdot \mathrm{h}^{-1}$ ).

The comparison group consisted of 17 consecutive patients who were paralyzed for the anesthesia as part of an elective surgical intervention. Exclusion criteria included pregnancy, a history of significant neuromuscular disease (multiple sclerosis; myasthenia gravis; muscular dystrophies), a known allergy to a non-depolarizing neuromuscular blocking agent, patients who received neuromuscular blocking agents or were taking a treatment known to influence the neuromuscular junction (anticonvulsants; antidepressants; antihistamines). For each patient, demographics and biological data were recorded. The creatinine clearance $(\mathrm{CrCl})$ was assessed by the simplified formula of the Modification of Diet in Renal Disease (sMDRD) [19].

In all patients, (elective surgical patients as well as the ICU patients) general anesthesia was induced with propofol ( 2.5 to $3 \mathrm{mg} \cdot \mathrm{kg}^{-1}$ ) and sufentanil ( 0.1 to $0.2 \mathrm{mg} \cdot \mathrm{kg}^{-1}$ ) and an initial bolus of cisatracurium at a dose of $0.15 \mathrm{mg} \cdot \mathrm{kg}^{-1}$. This was followed by a propofol infusion and repeated injections of $0.03 \mathrm{mg} \cdot \mathrm{kg}^{-1}$ cisatracrurium every four minutes until complete muscle paralysis $(\mathrm{TOF}=0)$ was achieved [20]. Monitoring of neuromuscular blockade was performed using a peripheral nerve stimulator with constant current using self-adhesive skin electrodes placed at the temporal region. A current of $60 \mathrm{~mA}$ (rectangular stimulation, pulse duration of 200 or 300 microseconds) was administered four times (TOF) at a frequency of $2 \mathrm{~Hz}$. An independent observer monitored the TOF semi-quantitatively by observing the contractile response of the corrugator supercilii every minute. The criterion for muscle relaxation was a complete absence of any twitch response. Any visible contraction was considered incomplete relaxation.

\section{Statistical analysis}

Based on a pilot study involving ten anesthetic patients and ten ICU patients, we estimated that the difference in dose to obtain adequate curarization was about $60 \%$. We calculated the number needed to find a difference of $60 \%$ in the dose of cisatracurium (in $\mathrm{mg}$ ) with an alpha of $5 \%$ and a power (1-beta) of $90 \%$ to be 16 patients in each group.

Statistical analysis was performed using the software StatView ${ }^{\circ}$ (SAS Institute Inc., version 5.0, Cary, NC, USA). Quantitative variables are presented as median (minimummaximum) and qualitative data are given as number and percentage. Normal distribution of data was tested via the Kolmogorov-Smirnov test. As data were not normally distributed, groups were compared by the Mann-Whitney $U$-test for continuous variables and by Fisher's exact test for categorical variables.

\section{Results}

Demographic and biological data are presented in Table 1. The reasons for ICU admission were: severe trauma (4); septic shock (1); acute respiratory failure (7); cerebral toxoplasmosis (1); aortic dissection (1); severe aortic stenosis (1); severe hyponatremia (1); and severe hypoglycemic coma (1). The ICU patients had been ventilated for $12 \pm 5$ days before they were included in the present study. No adverse cardiovascular events or signs of histamine release 
Table 1 Demographic and biologic data

\begin{tabular}{|c|c|c|c|}
\hline & $\begin{array}{l}\text { ICU patients } \\
\qquad N=17\end{array}$ & $\begin{array}{l}\text { Surgical patients } \\
\qquad N=17\end{array}$ & $P$ \\
\hline Age (years) & 60 (28 to 83 ) & 56 (26 to 86$)$ & 0.89 \\
\hline $\operatorname{Sex}(M / F)$ & $13 / 4$ & $11 / 6$ & 0.88 \\
\hline Weight (kg) & 75 (55 to 128$)$ & 71 (51 to 83 ) & 0.076 \\
\hline Height $(\mathrm{cm})$ & $160(144$ to 175$)$ & 169 (158 to 186$)$ & 0.099 \\
\hline BMI & 29 (27 to 39$)$ & 26 (22 to 37$)$ & 0.083 \\
\hline Urea $\left(\mathrm{mmol} . \mathrm{L}^{-1}\right)$ & 10.9 (3.60 to 31$)$ & 6 (3.4 to 23.6) & $0.02^{\mathrm{a}}$ \\
\hline Creatinine $\left(\mu \mathrm{mol} . \mathrm{L}^{-1}\right)$ & 84 (41 to 211$)$ & 88.50 (63.6 to 407$)$ & 0.67 \\
\hline $\begin{array}{l}\text { Creatinine clearance } \\
\left(\mathrm{ml} \cdot \mathrm{min}^{-1} .1 .73 \mathrm{~m}^{2-1}\right)\end{array}$ & 86.7 (29.8 to 159.4$)$ & 76.6 (13 to 113.4$)$ & 0.42 \\
\hline Prothrombin rate & 66 (20 to 89$)$ & 87 (64 to 100$)$ & $0.001^{\mathrm{a}}$ \\
\hline SGOT (IU.L-1') & $40(14$ to 274$)$ & $34(14$ to 183$)$ & 0.33 \\
\hline SGPT (IU.L-1 $)$ & 44 (15 to 425$)$ & 57 (13 to 293$)$ & 0.52 \\
\hline Protein $\left(g \cdot L^{-1}\right)$ & 55 (35 to 65$)$ & 71 (60 to 80 ) & $<0.001^{a}$ \\
\hline
\end{tabular}

Data are presented as median (minimum - maximum); ${ }^{a} P<0.05$ using the Mann-Whitney U-test.

were observed in the two groups after administration of cisatracurium.

After the initial dose of cisatracurium, none of ICU patients $(0 / 17)$ versus $15 / 17$ anesthesia patients were completely paralyzed $(P<0.0001)$.

The time to achieve complete neuromuscular blockade (after the initial dose of $0.15 \mathrm{mg} \cdot \mathrm{kg}^{-1}$ followed by repeated injections of $0.03 \mathrm{mg} \cdot \mathrm{kg}^{-1}$ every four minutes) was much longer in ICU patients when compared to surgical patients: $34 \pm 21$ versus $4 \pm 2$ minutes respectively $(P<0.0001$; Figure 1) and the total cumulative dose of cisatracurium was significantly higher in ICU patients when compared to surgical patients: $38 \pm 14 \mathrm{mg}$ versus $11 \pm 2 \mathrm{mg}$ respectively $(P<0.0001$; Figure 2).

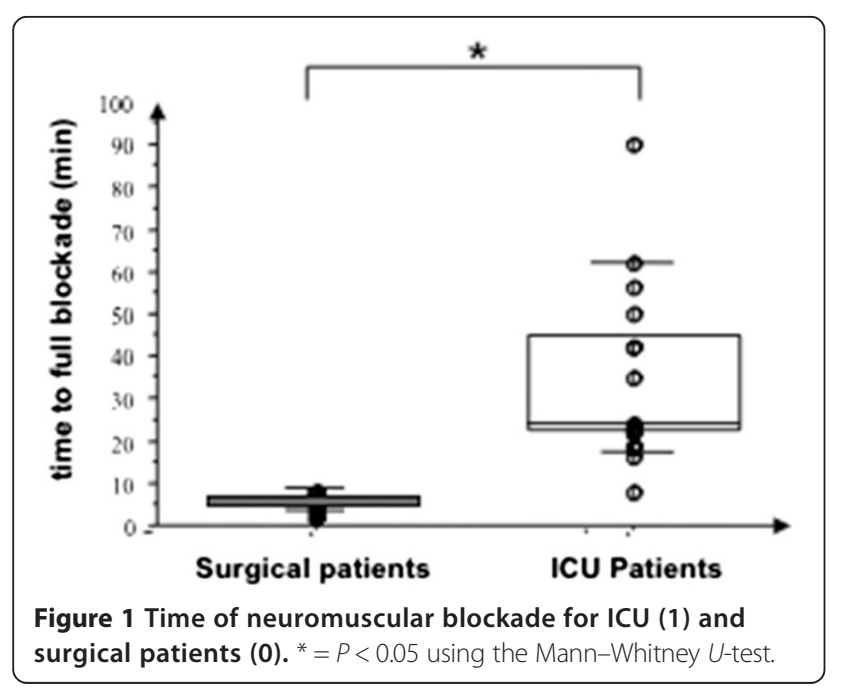

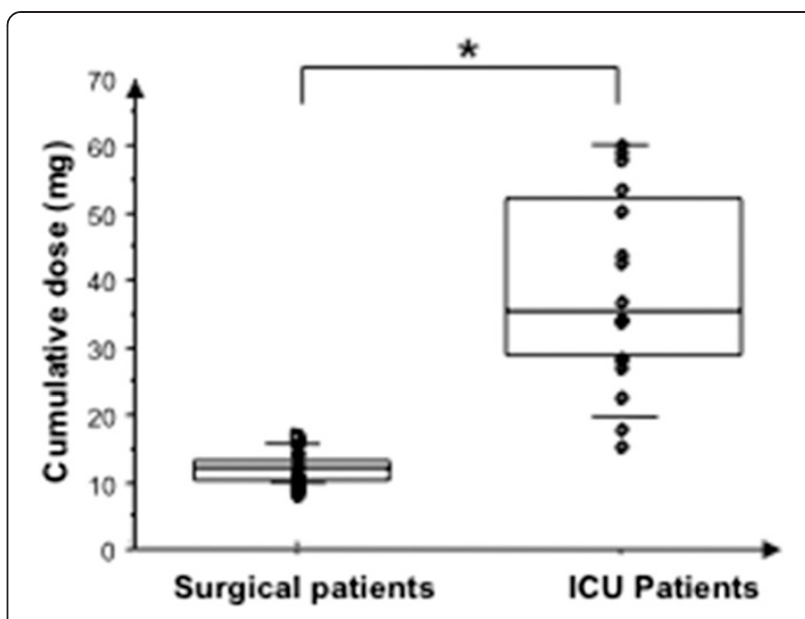

Figure 2 Cumulative doses of cisatracurium for ICU (1) and surgical patients $(0) .{ }^{*}=P<0.05$ using the Mann-Whitney $U$-test.

\section{Discussion}

This is the first study comparing the dose of muscle relaxant needed between ICU patients and surgical patients. We found that the time to achieve a complete neuromuscular block after an initial dose of $0.15 \mathrm{mg} \cdot \mathrm{kg}^{-1}$ followed by additional smaller repeat doses was longer in ICU patients when compared to surgical patients. We also showed that the cumulative doses of cisatracurium required to obtain a TOF $=0$ were significantly higher in ICU patients.

The results observed in our surgical patients are consistent with other published studies [12-14]. Increasing doses of cisatracurium can shorten the time to obtain a $\mathrm{TOF}=0$ [12-14]. ICU studies regarding the pharmacokinetics and pharmacodynamics of cisatracurium focused on patients receiving continuous infusions of cisatracurium [1] and mostly described the recovery profiles after continuous administration $[21,22]$. The doses used in those publications were a bolus of $0.1 \mathrm{mg} \cdot \mathrm{kg}^{-1}(2 \times$ ED95) with an average rate of infusion of $2.6 \mathrm{mg} \cdot \mathrm{kg}^{-1} \cdot \mathrm{min}^{-1}\left(0.15 \mathrm{mg} \cdot \mathrm{kg}^{-1} \cdot \mathrm{h}^{-1}\right)$ or $3.2 \mathrm{mg} \cdot \mathrm{kg}^{-1} \cdot \mathrm{min}^{-1}\left(0.19 \mathrm{mg} \cdot \mathrm{kg}^{-1} \cdot \mathrm{h}^{-1}\right)$ as required to obtain a sufficient degree of neuromuscular blockade for mechanical ventilation $[21,22]$. In comparison, the maintenance of muscle relaxation during anesthesia for a $95 \%$ depression of muscle contraction has been shown to range between $1.4 \mathrm{mg} \cdot \mathrm{kg}^{-1} \cdot \mathrm{min}^{-1}\left(0.08 \mathrm{mg} \cdot \mathrm{kg}^{-1} \cdot \mathrm{h}^{-1}\right)$ [12] and $1.5 \mathrm{mg} \cdot \mathrm{kg}^{-1} \cdot \mathrm{min}^{-1}\left(0.09 \mathrm{mg} \cdot \mathrm{kg}^{-1} \cdot \mathrm{h}^{-1}\right)$ [23]. This suggests that the rate of continuous infusion required to obtain muscle relaxation is greater in ICU patients when compared to surgical patients.

The evaluation of cumulative dosing of neuromuscular blocking agents is one method to determine dose-response studies; however this method has limitations because the elimination process begins while subsequent doses of cisatracurium would continue to be administered and therefore recovery of neuromuscular blockade occurs during re-administration of cisatracurium. No study has so far 
compared the time required for muscle relaxation or the doses required to reach a maximum block after administration of boluses of cisatracurium in ICU patients when compared to surgical patients, but our results seem to be consistent with those described for the continuous infusion of muscle relaxants. In fact, the onset time may have been shorter if ICU patients had received a higher initial bolus dose. Thereby, our study only shows that in ICU patients the initial dose $0.15 \mathrm{mg} \cdot \mathrm{kg}^{-1}$ was not adequate.

In ICU patients, a change in pharmacokinetics of cisatracurium may explain slower onset of paralysis and the need to administer larger doses. Indeed, Boyd et al. showed that the volume of distribution ( 21.9 versus $9.2 \mathrm{~L}$ ) and total clearance (549 versus 293 mL.min ${ }^{-1}$ ) of cisatracurium are higher in ICU patients when compared with anesthesia [21], when the half-life of the drug remained unchanged [21]. In ICU patients, an increased volume of distribution could lead to a decrease in the concentration at the neuromuscular junction after the first dose and this may therefore explain the need to administer larger doses. Another explanation could be a deregulation of acetylcholine receptors in ICU patients [24]. This would involve qualitative and quantitative changes of the acetylcholine receptor of the neuromuscular junction [25]. An increase in the number of acetylcholine receptors (up-regulation), a proliferation of the receptors at the neuromuscular junction and the rest of the muscle membrane, but also the formation of neoreceptors were observed [24,26]. Neoreceptors differ from the native receptor by substitution of the e-subunit by the g-subunit [25] and are more resistant to the action of nondepolarizing neuromuscular blocking [27]. The result is a decreased sensitivity to nondepolarizing neuromuscular blocking agents and a requirement for larger doses to observe the same effect. This effect could in part explain the findings in the present study since our ICU patients had already been admitted and ventilated for $12 \pm 5$ days before they were studied.

In ICU patients, many others factors could interfere with the effect of neuromuscular blocking agents, for example the presence of hypokalemia, hypercalcemia, hypothermia, treatment with magnesium sulfate, and so on. However, in our study, the ICU patients were considered stable so these factors were unlikely to have played a significant role. This should be taken into account for future studies.

Our study has several limitations. First, in the absence of pharmacokinetic data no definitive conclusion regarding the etiology for the difference between groups can be drawn from this report. Second, this was an observational and not a randomized study.

\section{Conclusion}

In summary, the doses of cisatracurium for ICU patients should be higher than those used in current anesthetic practice in order to achieve an adequate degree of neuromuscular blockade. This phenomenon could be related to changes in pharmacodynamics (deregulation of receptors) and pharmacokinetics (increase in the volume of distribution). Our data suggest that neuromuscular monitoring should be used to ensure a satisfactory degree of neuromuscular blockade in ICU patients requiring deep neuromuscular relaxation $(\mathrm{TOF}=0)$ for surgical procedures.

Further dose-response studies are required to determine the optimal loading dose of cisatracurium in ICU patients.

\section{Key messages:}

- Repeated boluses and more time are necessary to achieve complete muscle relaxation in ICU patients if using the same dose as for the routine induction of anesthesia.

- Doses of cisatracurium should be higher than those used in current anesthetic practice for an adequate degree of neuromuscular blockade.

- It seems reasonable to recommend monitoring neuromuscular blockade in ICU patients.

\section{Abbreviations}

ARDS: Acute respiratory distress syndrome; $\mathrm{CrCl}$ : Creatinine clearance; sMDRD: Simplified Modification of Diet in Renal Disease; TOF: Train-of-four.

\section{Competing interests}

The authors declare that they have no competing interests.

\section{Authors' contributions}

$E D, C C$ and PC carried out the patients' inclusions. KA helped to draft the manuscript and reviewed the intellectual content. BG and OF participated in the design of the study and helped to draft the manuscript. JMC and VM conceived of the study, and participated in its design and coordination, helped to draft the manuscript and performed the statistical analysis. All authors read and approved the final manuscript.

\section{Acknowledgements}

Funding Support was provided solely from institutional and department sources. The authors thank Dr. Matt Kurrek for review and editorial assistance.

\section{Author details}

'Department of Anesthesiology and Intensive Care Medicine, Faculté de Médecine Toulouse-Rangueil, EA 4564-MATN, Institut Louis Bugnard (IFR 150), CHU Toulouse, Université Toulouse III Paul Sabatier, F-31000 Toulouse, France. ${ }^{2}$ Department of Anesthesiology and Intensive Care Medicine, $\mathrm{CHU}$ Nantes, Nantes, France.

Received: 9 August 2013 Accepted: 7 January 2014 Published: 11 February 2014

\section{References}

1. Papazian L, Forel J-M, Gacouin A, Penot-Ragon C, Perrin G, Loundou A, Jaber S, Arnal J-M, Perez D, Seghboyan J-M, Constantin J-M, Courant P, Lefrant J-Y, Guérin C, Prat G, Morange S, Roch A, ACURASYS Study Investigators: Neuromuscular blockers in early acute respiratory distress syndrome. N Engl J Med 2010, 363:1107-1116.

2. Boyd AH, Eastwood NB, Parker CJ, Hunter JM: Pharmacodynamics of the $1 \mathrm{R}$ cis-1'R cis isomer of atracurium (51 W89) in health and chronic renal failure. Br J Anaesth 1995, 74:400-404. 
3. De Wolf AM, Freeman JA, Scott VL, Tullock W, Smith DA, Kisor DF, Kerls S, Cook DR: Pharmacokinetics and pharmacodynamics of cisatracurium in patients with end-stage liver disease undergoing liver transplantation. Br J Anaesth 1996, 76:624-628.

4. Lien CA, Schmith VD, Belmont MR, Abalos A, Kisor DF, Savarese JJ: Pharmacokinetics of cisatracurium in patients receiving nitrous oxide/ opioid/barbiturate anesthesia. Anesthesiology 1996, 84:300-308.

5. Eastwood NB, Boyd AH, Parker CJ, Hunter JM: Pharmacokinetics of 1R-cis 1' R-cis atracurium besylate ( 51 W89) and plasma laudanosine concentrations in health and chronic renal failure. Br J Anaesth 1995, 75:431-435.

6. Klessig HT, Geiger HJ, Murray MJ, Coursin DB: A national survey on the practice patterns of anesthesiologist intensivists in the use of muscle relaxants. Crit Care Med 1992, 20:1341-1345.

7. Sharpe MD: The use of muscle relaxants in the intensive care unit. Can $J$ Anaesth 1992, 39:949-962

8. Meistelman C, Plaud B: Neuromuscular blockade: is it still useful in the ICU? Eur J Anaesthesio/ Supp/ 1997, 15:53-56.

9. Sapirstein A, Hurford WE: Neuromuscular blocking agents in the management of respiratory failure. Indications and treatment guidelines. Crit Care Clin 1994, 10:831-843.

10. Shapiro BA, Warren J, Egol AB, Greenbaum DM, Jacobi J, Nasraway SA, Schein RM, Spevetz A, Stone JR: Practice parameters for sustained neuromuscular blockade in the adult critically ill patient: an executive summary. Society of critical care medicine. Crit Care Med 1995, 23:1601-1605.

11. Miller RD: Use of neuromuscular blocking drugs in intensive care unit patients. Anesth Analg 1995, 81:1-2.

12. Belmont MR, Lien CA, Quessy S, Abou-Donia MM, Abalos A, Eppich L, Savarese Jj: The clinical neuromuscular pharmacology of 51 W89 in patients receiving nitrous oxide/opioid/barbiturate anesthesia. Anesthesiology 1995 82:1139-1145.

13. Lepage JY, Malinovsky JM, Malinge M, Lechevalier T, Dupuch C, Cozian A, Pinaud M, Souron R: Pharmacodynamic dose-response and safety study of cisatracurium (51 W89) in adult surgical patients during N2O-O2-opioid anesthesia. Anesth Analg 1996, 83:823-829.

14. Bluestein LS, Stinson LW, Lennon RL, Quessy SN, Wilson RM: Evaluation of cisatracurium, a new neuromuscular blocking agent, for tracheal intubation. Can J Anaesth 1996, 43:925-931.

15. Littlejohn $\mathrm{H}$, Abhay K, Sayedel A, Broomhead CJ, Duvaldestin P, Flynn PJ: Intubating conditions following 1R CIS, 1'R CIS atracurium (51W89). A comparison with atracurium. Anaesthesia 1995, 50:499-502.

16. Beemer $\mathrm{GH}$, Bjorksten AR: Pharmacodynamics of atracurium in clinical practice: effect of plasma potassium, patient demographics, and concurrent medication. Anesth Analg 1993, 76:1288-1295.

17. Waud BE, Waud DR: Interaction of calcium and potassium with neuromuscular blocking agents. Br J Anaesth 1980, 52:863-866.

18. Vanderheyden BA, Reynolds HN, Gerold KB, Emanuele T: Prolonged paralysis after long-term vecuronium infusion. Crit Care Med 1992, 20:304-307.

19. Levey AS, Bosch JP, Lewis JB, Greene T, Rogers N, Roth D: A more accurate method to estimate glomerular filtration rate from serum creatinine: a new prediction equation. Modification of diet in renal disease study group. Ann Intern Med 1999, 130:461-470.

20. Melloni C, Devivo P, Launo C, Mastronardi P, Novelli GP, Romano E: Cisatracurium versus vecuronium: a comparative, double blind, randomized, multicenter study in adult patients under propofol/ fentanyl/N2O anesthesia. Minerva Anestesiol 2006, 72:299-308.

21. Boyd AH, Eastwood NB, Parker CJ, Hunter JM: Comparison of the pharmacodynamics and pharmacokinetics of an infusion of cis-atracurium (51 W89) or atracurium in critically ill patients undergoing mechanical ventilation in an intensive therapy unit. Br J Anaesth 1996, 76:382-388.

22. Prielipp RC, Coursin DB, Scuderi PE, Bowton DL, Ford SR, Cardenas VJ, Vender J, Howard D, Casale EJ, Murray MJ: Comparison of the infusion requirements and recovery profiles of vecuronium and cisatracurium 51 W89 in intensive care unit patients. Anesth Analg 1995, 81:3-12.

23. Mellinghoff $H$, Radbruch $L$, Diefenbach $C$, Buzello W: A comparison of cisatracurium and atracurium: onset of neuromuscular block after bolus injection and recovery after subsequent infusion. Anesth Analg 1996, 83:1072-1075.

24. Martyn JA, White DA, Gronert GA, Jaffe RS, Ward JM: Up-and-down regulation of skeletal muscle acetylcholine receptors. Effects on neuromuscular blockers. Anesthesiology 1992, 76:822-843.
25. Hogue CW, Ward JM, Itani MS, Martyn JA: Tolerance and upregulation of acetylcholine receptors follow chronic infusion of d-tubocurarine. J Appl Physiol 1992, 72:1326-1331.

26. Danon MJ, Carpenter S: Myopathy with thick filament (myosin) loss following prolonged paralysis with vecuronium during steroid treatment. Muscle Nerve 1991, 14:1131-1139.

27. Ibebunjo C, Nosek MT, Itani MS, Martyn JA: Mechanisms for the paradoxical resistance to d-tubocurarine during immobilization-induced muscle atrophy. J Pharmacol Exp Ther 1997, 283:443-451.

doi:10.1186/2110-5820-4-3

Cite this article as: Dieye et al:: Pharmacodynamics of cisatracurium in the intensive care unit: an observational study. Annals of Intensive Care 2014 4:3.

\section{Submit your manuscript to a SpringerOpen ${ }^{\circ}$ journal and benefit from:}

- Convenient online submission

- Rigorous peer review

- Immediate publication on acceptance

- Open access: articles freely available online

- High visibility within the field

- Retaining the copyright to your article

Submit your next manuscript at $>$ springeropen.com 